\title{
CYBERBULLYING EM ESTUDANTES DO ENSINO MÉDIO EM JUAZEIRO-BA
}

\author{
Cyberbullying in high school students in Juazeiro-BA
}

Cyberbullying en estudiantes de secundaria en Juazeiro-BA

\author{
Liberalina Santos de Souza Gondim \\ Marcelo Silva de Souza Ribeiro \\ Universidade Federal do Vale do São Francisco
}

\begin{abstract}
RESUMO
O cyberbullying é uma nova forma de bullying em que as Tecnologias da Informação e Comunicação (TICs) são utilizadas para intimidar pessoas. Esta pesquisa utilizou um delineamento quantitativo descritivo e teve como objetivo identificar manifestações de cyberbullying entre alunos do ensino médio de uma escola particular na cidade de Juazeiro-BA. Participaram 46 estudantes do ensino médio entre 14 e 19 anos que responderam a um questionário sobre uso das tecnologias e violência online. A análise foi feita por estatística descritiva. Os resultados mostram níveis consideráveis de agressões online, sendo 18 (39\%) vítimas e $12(26 \%)$ agressores. As estratégias de enfrentamento utilizadas pelos jovens foram prioritariamente individuais, como chorar (39\%), não reagir (28\%), ou responder da mesma forma (22\%), demonstrando-se limitadas para lidar com o fenômeno. As repercussões das experiências foram principalmente de ordem psicológica $(91 \%)$ e social $(64 \%)$. Considera-se a necessidade de ações intersetoriais de prevenção e enfrentamento ao cyberbullying.
\end{abstract}

Palavras-chave: Bullying; Cyberbullying; Adolescentes.

\begin{abstract}
Cyberbullying is a new form of bullying in which Information and Communication Technologies (Tecnologias da Informação e Comunicação - TICs, in Brazil) are used to intimidate people. This research used a descriptive quantitative delineation and aimed to identify manifestations of cyberbullying among high school students of a private school in the city of Juazeiro-BA. This is a quantitative and descriptive research with 46 high school students aged between 14 and 19 who answered a questionnaire about the use of technologies and experiences of online violence. The analysis was made by descriptive statistics. The results show considerable levels of online aggression, with 18 (39\%) victims and $12(26 \%)$ aggressors. The coping strategies used by the youngsters were primarily individual, such as crying $(39 \%)$, not responding $(28 \%)$, or responding in the same way $(22 \%)$, proving themselves limited to cope with the phenomenon. The repercussions of the experiences mainly of psychological order $(91 \%)$ and social $(64 \%)$. It is considered necessary the development of actions of prevention and coping with cyberbullying involving articulation between fields of health, education and technologies.
\end{abstract}

Keywords: Bullying; Cyberbullying; Adolescents. 


\section{RESUMEM}

El cyberbullying es una nueva forma de bullying en que las Tecnologías de la Información y la Comunicación (Tecnologias da Informação e Comunicação TICs, en Brasil) se utilizan para intimidar a las personas. Esta investigación utilizó un delineamiento cuantitativo descriptivo y tuvo como objetivo identificar manifestaciones de cyberbullying entre alumnos de la escuela secundaria de una escuela particular en la ciudad de Juazeiro-BA. Se trata de una investigación cuantitativa y descriptiva con 46 estudiantes de la enseñanza media entre 14 y 19 años que respondieron a un cuestionario sobre el uso de las tecnologías y vivencias de violencia online. El análisis fue realizado por estadística descriptiva. Los resultados muestran niveles considerables de agresiones en línea, siendo 18 $(39 \%)$ víctimas y $12(26 \%)$ agresores. Las estrategias de enfrentamiento utilizadas por los jóvenes fueron prioritariamente individuales, como llorar (39\%), no reaccionar $(28 \%)$, o responder de la misma forma $(22 \%)$, demostrándose limitadas para lidiar con el fenómeno. Las repercusiones de las experiencias principalmente de orden psicológico (91\%) y social $(64 \%)$. Se considera la necesidad del desarrollo de acciones de prevención y enfrentamiento al cyberbullying involucrando articulación entre los campos de la salud, la educación y las tecnologías.

Palabras clave: Bullying; Cyberbullying; Adolescentes.

\section{INTRODUÇÃO}

Desde o final do século XX, as Tecnologias da Informação e Comunicação (TICs) têm avançado de maneira extraordinária, modificando a forma de organização da vida em sociedade, incluindo transformações em níveis culturais, comportamentais, econômicos e políticos. Tais avanços, que continuam em andamento, trazem contribuições positivas ao facilitar o acesso a todo tipo de informação, produtos e serviços, superando, inclusive, antigas fronteiras do espaço-tempo no que se refere às comunicações tradicionais (Almeida, 2009). Por outro lado, consequências negativas aparecem em fenômenos como a dependência tecnológica, violência virtual, o cyberbullying, cybercrimes, entre outros, que causam repercussões físicas, psicológicas e sociais, de modo a demandar investigações mais profundas, além da criação de medidas resolutivas (Andrade, 2012; Conte \& Rossini, 2010; Dal Cin, 2013; Wendt \& Lisboa, 2013).

Entende-se por Tecnologias da Informação e Comunicação (TICs) "todo e qualquer dispositivo que tenha capacidade para tratar dados e/ou informações, tanto de forma sistêmica como esporádica, quer esteja aplicada no produto, quer esteja aplicada no processo" (Cruz, 2000, p. 24). Porém, as novas tecnologias envolvem não apenas esses dispositivos em constante transformação, mas também um processo social, a atividade multiforme de grupos humanos, um devir coletivo complexo que se cristaliza em volta de programas e dispositivos de comunicação e causam impactos tanto positivos como negativos na sociedade (Lévy, 1999). 
Com a criação e difusão do computador e da internet e com a reestruturação socioeconômica dos anos 1980, a sociedade passou a se reorganizar, transformando-se no que Casttels (1999) chama de sociedade em rede. Para esse autor, a sociedade em rede constitui-se em um movimento que tem a Internet como principal veículo para a transmissão de informações, envolve uma cultura própria que engloba uma diversidade de subculturas, organizando-se em torno das mídias e dos novos dispositivos tecnológicos (Casttels, 1999).

Dialogando com esta visão da sociedade atual, Lévy (1999) descreve o conceito de cibercultura ${ }^{1}$ como um conjunto de técnicas, práticas, atitudes e valores que se desenvolve junto com as novas tecnologias e com o ambiente de comunicação online, chamado de ciberespaço. Para ele, com a virtualização das relações, uma inteligência coletiva é construída, estabelecida e reformulada em tempo real, formando uma espécie de cérebro global, do qual cada vez mais pessoas sentem necessidade de fazer parte.

Uma pesquisa realizada pelo Comitê Gestor da Internet no Brasil - CGI.br aponta que tais mudanças afetam de forma mais intensa crianças e adolescentes, dos quais cerca de $75 \%$ utilizam todos os dias mensagens instantâneas como o WhatsApp e $63 \%$ acessam redes sociais, como o Facebook com a mesma frequência (Barbosa, 2014). São os chamados nativos digitais, sobretudo porque crescem em meio a dispositivos cada vez mais desenvolvidos e que influenciam suas formas de relacionamento com o mundo a sua volta, gerando oportunidades, mas também riscos.

O cyberbullying vem sendo considerado uma modalidade do bullying diante da evolução tecnológica e do uso constante de dispositivos móveis. Porém, possui aspectos específicos que mudam qualitativamente as formas tradicionais da agressão entre pares (Brown, Jackson \& Cassidy, 2006). O bullying pode ser caracterizado como um tipo de comportamento agressivo marcado pela forma intencional, repetitiva e sem motivação aparente pela qual ocorre, além de estar ligado ao contexto escolar e envolver um desequilíbrio de poder (Olweus, 1997).

Para Willard (2007, apud Andrade, 2012), existem sete tipos de manifestações de cyberbullying, são elas: as lutas online, nas quais são trocados mensagens ou comentários hostis entre duas ou mais pessoas; o assédio virtual, de caráter unidirecional e repetitivo, são enviadas mensagens ou publicações ofensivas; a difamação, ou seja, divulgação na internet de boatos sobre alguém com a intenção de prejudicá-la; a representação ou personificação, por meio de infiltração na conta da vítima para enviar informações constrangedoras ou que a deixe em perigo; as partilhas pessoais e embaraçosas, em que são compartilhados assuntos íntimos sobre alguém, podendo envolver ameaças à vítima; a exclusão, por expulsão de um

\footnotetext{
${ }^{1}$ Alguns autores usam os termos cibercultura / ciberbullying com o padrão da língua portuguesa, outros descrevem cybercultura / cyberbullying com o padrão da língua inglesa, porém preserva-se o mesmo significado nas duas formas de grafia.
}

Rev. Nufen: Phenom. Interd. | Belém, 11(1), 102-121, jan. - abr., 2019. 
grupo online de forma cruel e humilhante; e a perseguição online, caracterizada por ameaças ou extorsão por meio da rede.

Porém, para ser considerado cyberbullying é necessário confirmar no comportamento agressivo a intencionalidade, a repetição ao longo do tempo, o sofrimento real da vítima e a utilização de meios eletrônicos (Patchin \& Hinduja, 2010). Além disso, nas situações de cyberbullying, é importante considerar os aspectos envolvidos no comportamento do agressor, pois a ausência de contato pessoal com as vítimas pode alimentar crenças de imunidade em relação a seus atos e dificultar a empatia, de modo que pode haver falhas no desenvolvimento de algumas habilidades sociais (Calvete, Orue, Estévez, Villardón \& Padilla, 2010).

Entretanto, para Rondina, Moura e Carvalho (2016), as práticas de cyberbulling estão antes de tudo relacionadas as funções psicológicas e a questões sociais. Nesse sentido, os autores apontam a menor qualidade de vida dos agressores, apesar de não haver prejuízos no relacionamento social, de modo que a internet e a disseminação da violência através dela funcionam como meios para lidarem com angústias internas, estresse e com o sofrimento.

Porém, a complexidade das relações online faz com que, em muitos casos, sejam difíceis de diferenciar vítimas e agressores, pois na dinâmica das relações, jovens que são frequentemente vítimas, podem, em algumas ocasiões, agir também como agressores e viceversa. Uma pesquisa de García-Maldonado, et al. (2012) encontrou, entre adolescentes estudantes, que $3,5 \%$ se declaram vítimas, $2,8 \%$ agressores e $1,3 \%$ vítimas-agressores virtuais. Se considerarmos que muitos não admitem ser agressores ou vítima-agressores devido à desaprovação social, esse número pode ser ainda maior. Em todos os casos, no ambiente virtual, as pessoas se tornam testemunhas e coparticipantes no processo de perpetuação da violência.

Diante desses aspectos, algumas consequências psicológicas do cyberbullying podem ser até mais devastadoras que as agressões presenciais (Andrade, 2012). Durante ou após o uso de tecnologias, os adolescentes que sofrem cyberbullying podem apresentar, entre outros aspectos, angústia, ansiedade ou apatia, reações impulsivas, além de reflexos negativos na vida escolar, como redução do rendimento e isolamento social (Souza \& Lima, 2016). Outros autores apontam ainda a existência de: estresse, tensão, desconfiança, insegurança, sentimentos de impotência e fragilidade, humilhação, pânico, impossibilidade de encarar os familiares e amigos, baixa autoestima, depressão e tentativa ou ideação suicida (Patchin \& Hinduja, 2010; Barbosa, 2014).

Para lidar com o cyberbullying e suas repercussões, considera-se a importância da articulação entre diversos atores sociais a fim de criar estratégias de enfretamento eficazes e resolutivas, especialmente no que diz respeito ao suporte, proteção e orientação. Estratégias de enfrentamento são esforços cognitivos e comportamentais para lidar com 
situações específicas, de modo a atuar sobre um fenômeno ou alterar o significado atribuído a ele (Castillo, 2010). Essas estratégias podem ser individuais ou coletivas.

Diante da complexidade das relações que envolvem o uso das TICs para o exercício da violência, esta pesquisa buscou identificar as manifestações de cyberbullying entre alunos do ensino médio de uma escola particular na cidade de Juazeiro-BA. Os objetivos específicos foram: descrever o padrão de uso da internet por destes jovens, identificar a ocorrência de repercussões biopsicossociais da violência online, e apontar estratégias as utilizadas por eles para lidar com o problema.

A originalidade da pesquisa encontra-se no fato que no Brasil as pesquisas sobre cyberbullying ainda são reduzidas, se comparadas a literatura internacional. Além disso, tendo em vista os aspectos psicossociais envolvidos nas formas de cyberbullying, torna-se relevante estudar suas manifestações no sertão nordestino, especificamente na cidade de Juazeiro da Bahia.

\section{MÉTODO}

Foi utilizada uma metodologia de pesquisa com um viés quantitativo e descritivo, no sentido de apreender informações sobre as vivências de cyberbullying entre adolescentes estudantes do ensino médio em uma escola particular na cidade de Juazeiro-BA. Segundo Fonseca (2002), a pesquisa quantitativa é objetiva e recorre a instrumentos padronizados e neutros para avaliar dados da realidade, descrever as causas de um fenômeno e as relações entre variáveis. Esta metodologia foi escolhida por se adequar aos objetivos de pesquisa e permitir investigar dados sobre o fenômeno de forma estruturada.

A escolha da escola alvo da pesquisa foi realizada por conveniência, tendo em vista a abertura da gestão para o acesso dos pesquisadores aos estudantes, devido parceria em projetos anteriores. A amostragem por conveniência é considerada um método para se obter participantes onde se puder encontra-los com maior facilidade, porém, devido a isso, a amostra não é representativa de todos os estudantes da cidade (Cozby, 2003). Além disso, a instituição recebe uma ampla quantidade de alunos provenientes de diversas localidades da cidade e alguns provenientes de cidades circunvizinhas, o que a torna adequada para os interesses do estudo.

A escola atende alunos do ensino fundamental II e ensino médio, funciona em período matutino e conta atualmente com um número total de 382 alunos, doa quais 149 estão cursando o ensino médio. Dispõe de rede wi-fi, mas esta só pode ser acessada pelos estudantes através dos computadores de mesa instalados na sala dos professores. Nas normas da escola, o uso de dispositivos móveis é permitido apenas durante o intervalo, ou para fins pedagógicos em sala de aula, com orientação do professor. 
Os colaboradores da pesquisa foram 46 adolescentes estudantes do ensino médio com idades entre 14 e 19 anos. Os pesquisadores estiveram em todas as salas de aulas do ensino médio, explicaram os objetivos da pesquisa e convidaram os estudantes para participar, entregando-Ihes um Termo de Consentimento Livre e Esclarecido, que devia ser assinado pelos alunos, e um Termo de Assentimento do Menor, que deveria ser assinado pelos pais ou responsáveis. Após a devolução de uma cópia assinada os dois termos, os colaboradores que aceitaram e tiveram a permissão dos responsáveis para participar da pesquisa, responderam a um questionário fechado construído especificamente para esta pesquisa com base nos estudos de Campos (2009), Oliveira (2012) e Soares (2013), abordando aspectos sociodemográficos, uso das tecnologias, vitimização e comportamento agressivo online. O questionário utilizado passou por algumas adaptações tendo em vista os objetivos deste estudo, além da avaliação de dois juízes, estudiosos na área de violência no contexto escolar, que verificaram a adequação dos itens aos interesses de pesquisa.

A primeira parte do questionário foi composta por dados sociodemográficos dos participantes, como idade, gênero, escolaridade, renda e com quem mora. A segunda parte foi correspondente ao padrão de uso das tecnologias pelos jovens, aplicativos e sites, horas de uso, e estratégias de segurança online. A terceira parte abordou aspectos da vitimização online, meios de intimidação, frequência, contato com o agressor, reações a violência e consequências para a vida. $\mathrm{Na}$ terceira parte do estudo, optou-se por utilizar senários hipotéticos de cyberbullying na tentativa de uma aproximação com as vivências enquanto agressor em situação de cyberbullying através de situações fictícias. Os cenários foram criados especificamente para este estudo, tendo em vista que, como demonstra a literatura, os agressores tem mais dificuldades de se reconhecerem como tais (Menay-López \& FuenteMella, 2014; Varela et al, 2014; Prieto et al, 2015).

Após uma breve explanação sobre os objetivos da pesquisa, esclarecimento de dúvidas, o questionário foi respondido coletivamente, em um espaço cedido pela escola e em datas e horários acordados com os adolescentes e a instituição. Durante a aplicação do instrumento com os estudantes, a pesquisadora buscou estabelecer um ambiente confortável, respeitoso e empático que fosse favorável e expressão de respostas autênticas e que mais se aproximassem das vivências dos alunos.

Os adolescentes foram selecionados de acordo com os seguintes critérios:

Ser adolescente entre 14 e 19 anos, estar cursando ensino médio na escola de estudo e fazer uso de dispositivos tecnológicos como computadores, smartphones, tablets ou Iphones. Foram excluídos da pesquisa os jovens que responderam aos questionários de forma inadequada, ou seja, deixou de responder itens importantes, como os presentes nos tópicos sobre uso das tecnologias, vitimização e agressões online, ou marcou mais de uma alternativa na mesma questão.

Rev. Nufen: Phenom. Interd. | Belém, 11(1), 102-121, jan. - abr., 2019. 
Esta pesquisa foi aprovada pelo Sistema do Comitê de Ética em Pesquisa CEPCONEP no dia 04 de abril de 2017, por meio do parecer 1.998 .179 e está registrada sob o n ${ }^{\circ}$ 63823317.2.0000.5196, respeitando as questões éticas pertinentes à pesquisa com seres humanos, a partir das Resoluções CONEP/MS 466/2012 e 510/2016. A pesquisa foi realizada no período de abril a dezembro de 2017.

Os dados obtidos nos questionários foram analisados por estatística descritiva. Ao lançar uso de informações quantitativas, não se pretende rotular ou categorizar, mas sim descrever informações, sobre o público estudado, pertinentes a uma melhor compreensão do fenômeno cyberbullying.

\section{RESULTADOS}

A partir do questionário aplicado foi possível obter algumas características sociodemográficas do público estudado, como demonstra a tabela 1 , a seguir.

Tabela 1. Distribuição dos jovens, segundo faixa etária e variáveis sociodemográficas

\begin{tabular}{|c|c|c|c|c|c|c|c|c|c|c|c|c|c|c|}
\hline \multicolumn{15}{|c|}{ Idade } \\
\hline Variáveis & \multicolumn{2}{|c|}{14} & \multicolumn{2}{|c|}{15} & \multicolumn{2}{|c|}{16} & \multicolumn{2}{|c|}{17} & \multicolumn{2}{|r|}{18} & \multicolumn{2}{|c|}{19} & \multicolumn{2}{|c|}{ Total } \\
\hline Gênero & $\mathrm{n}$ & $\%$ & $\mathrm{n}$ & $\%$ & $\mathrm{~N}$ & $\%$ & $\mathrm{n}$ & $\%$ & $\mathrm{n}$ & $\%$ & $\mathrm{n}$ & $\%$ & $\mathrm{n}$ & $\%$ \\
\hline Masculino & 1 & 5,3 & 5 & 26,3 & 8 & 42,1 & 3 & 15,8 & 1 & 5,3 & 1 & 5,3 & 19 & 41,3 \\
\hline Feminino & 4 & 14,8 & 12 & 44,4 & 7 & 25,9 & 4 & 14,8 & - & - & - & - & 27 & 58,7 \\
\hline \multicolumn{15}{|c|}{ Grau de Escolaridade } \\
\hline $1^{0}$ Ano & 5 & 27,8 & 10 & 55,6 & 3 & 16,7 & - & - & - & - & - & - & 18 & 39,1 \\
\hline $2^{\circ}$ Ano & - & - & 7 & 43,8 & 9 & 56,3 & - & - & - & - & - & - & 16 & 34,8 \\
\hline $3^{0}$ Ano & - & - & - & - & 3 & 25,0 & 7 & 58,3 & 1 & 8,3 & 1 & 8,3 & 12 & 26,1 \\
\hline \multicolumn{15}{|l|}{ Renda Média } \\
\hline \multicolumn{15}{|l|}{ Familiar $^{*}$} \\
\hline Sem Resposta & 1 & 4,0 & 10 & 40,0 & 10 & 40,0 & 3 & 12,0 & - & - & 1 & 4,0 & 25 & 54,3 \\
\hline Nenhuma renda & - & - & - & - & - & - & - & - & - & - & - & - & - & - \\
\hline A té 1 salário & - & - & - & - & - & - & - & - & - & - & - & - & - & - \\
\hline De 1 a 3 salários & 3 & 27,3 & 5 & 45,5 & 3 & 27,3 & - & - & - & - & - & - & 11 & 23,9 \\
\hline De 3 a 6 salários & - & - & 2 & 40,0 & - & - & 3 & 60,0 & - & - & - & - & 5 & 10,9 \\
\hline De 6 a 9 salários & - & - & - & - & 2 & 66,7 & - & - & 1 & 33,3 & - & - & 3 & 6,5 \\
\hline De 9 a 12 salários & - & - & - & - & - & - & 1 & 100 & - & - & - & - & 1 & 2,2 \\
\hline $\begin{array}{c}\text { Mais de } 12 \\
\text { salários }\end{array}$ & 1 & 100 & - & - & - & - & - & - & - & - & - & - & 1 & 2,2 \\
\hline \multicolumn{15}{|l|}{ Com quem vive } \\
\hline Seus pais & 3 & 11,1 & 9 & 33,3 & 10 & 37,0 & 5 & 18,5 & - & - & - & - & 27 & 58,7 \\
\hline Sua mãe & 2 & 12,5 & 8 & 50,0 & 4 & 25,0 & 2 & 12,5 & - & - & - & - & 16 & 34,8 \\
\hline Seu pai & - & - & - & - & - & - & - & - & 1 & 100 & - & - & 1 & 2,2 \\
\hline Sozinho & - & - & - & - & - & - & - & - & - & - & 1 & 100 & 1 & 2,2 \\
\hline Avós & - & - & - & - & 1 & 100 & - & - & - & - & - & - & 1 & 2,2 \\
\hline
\end{tabular}

*Nota: Salário mínimo: R\$937,00

Rev. Nufen: Phenom. Interd. | Belém, 11(1), 102-121, jan. - abr., 2019. 
Participaram da pesquisa 27 meninas e 19 meninos. Destaca-se a prevalência das faixas etárias entre 15 e 16 anos, representada por 17 (37\%) e 15 (33\%) adolescentes da amostra, respectivamente. A média de idade foi de 15,67 anos com um desvio padrão de 1,07. Em relação ao gênero, a maioria dos colaboradores se identificou com o gênero feminino, 28 (61\%), enquanto apenas 18 (39\%) com o gênero masculino.

No que se refere à escolaridade, houve mais colaboradores no $1^{\circ}$ ano do ensino médio, $18(39 \%)$, seguidos de $16(35 \%)$ estudantes do $2^{\circ}$ ano e $12(26 \%)$ estudantes do $3^{\circ}$ ano. Já no que diz respeito à renda familiar, 25 (54\%) dos estudantes não souberam responder quanto os seus pais ou responsáveis ganham, o que dificultou verificar com precisão questões relacionadas à renda média familiar. Porém, $12(26 \%)$ alunos descrevem uma renda entre 1 e 3 salários mínimos; quatro (9\%) entre 3 e 6 salários; três (7\%) entre 6 e 9 salários e dois (4\%) relatam uma renda familiar de mais de 12 salários mínimos, o que demonstra uma diversidade de classes sociais entre os estudantes.

A maioria dos alunos, 27 (59\%), afirmam viver com ambos os pais, enquanto 16 (35\%) vivem apenas com a mãe. Apenas um aluno relatou que vive com o seu pai, um respondeu que mora sozinho e outro que mora com os seus avós.

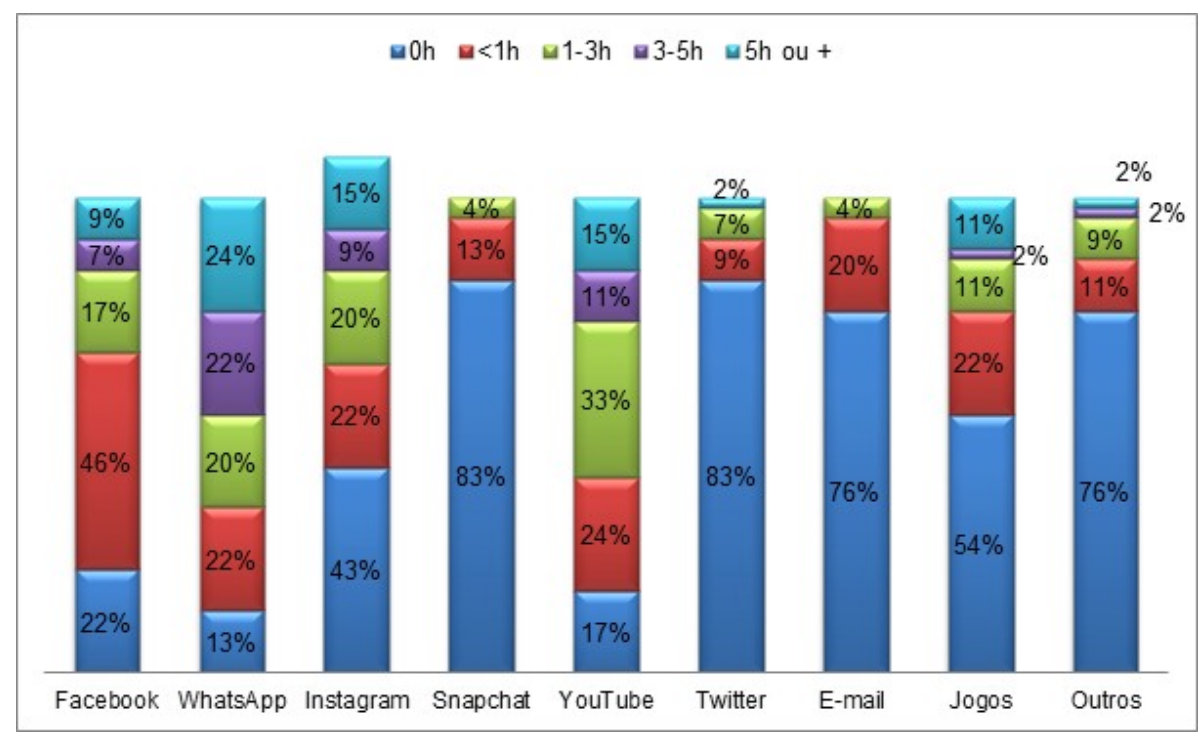

Figura 1. Horas de uso da internet por dia

Fonte: Dados da pesquisa.

Com relação ao uso das TICs pelos jovens investigados, no que diz respeito ao tempo que gastam online em sites ou aplicativos através da internet, destaca-se o uso de sites e aplicativos populares como a rede de relacionamentos Facebook, a plataforma de conversas instantâneas WhatsApp, o aplicativo de compartilhamentos de fotos Instagram e o site de 
compartilhamentos de vídeos Youtube. Entre os adolescentes pesquisados, 21(46\%) relatam utilizar o Facebook cerca de uma hora por dia, 11 (24\%) afirmam usar o Youtube e 10 (22\%) utilizam o WhatsApp, Instagram ou acessam jogos com a mesma frequência.

Outros $15(33 \%)$ colaboradores afirmam utilizar o Youtube entre uma e três horas por dia e $10(22 \%)$ chegam a utilizar o Facebook entre três e cinco horas por dia. Porém, chamam ainda mais atenção aqueles jovens que utilizam as TICs mais de cinco horas por dia, como no caso dos 11 (24\%) que relataram usar o WhatsApp com essa frequência, além dos $7(15 \%)$ que usam o Instagram ou o Youtube e dos cinco (11\%) estudantes que acessam jogos mais de cinco horas durante o dia.

Quando questionados sobre o conhecimento de estratégias de segurança no ciberespaço, $37(80 \%)$ dos colaboradores relataram que sim e outros 09 (20\%) que não conhecem tais estratégias. Entre os mecanismos mais utilizados pelos estudantes estão: não abrir links ou anexos de pessoas desconhecidas e não partilhar informação pessoal com desconhecidos. As duas situações foram utilizadas por 29 (63\%) colaboradores; denunciar páginas com conteúdo inadequado, relatado por 23 (50\%) jovens; evitar ter conversas privadas com pessoas desconhecidas, 17 (37\%) adolescentes; usar software que proteja de conteúdos indesejáveis e bloquear ou não adicionar e-mails desconhecidos, ambas são ferramentas usadas por $13(28 \%)$ deles.

No que diz respeito aos processos de vitimização online, 28 (61\%) afirmaram que nunca foram alvos de insultos, ameaças, constrangimentos ou perseguições na internet. Porém, outros $18(39 \%)$ relataram que sim, já foram alvos de um tipo de intimidação virtual. Entre estes, o meio mais relatado das vivências de violência foi o site de relacionamentos Facebook, 11 (61\%) pessoas, seguido da plataforma de mensagens instantâneas WhatsApp, seis $(33 \%)$ dos colaboradores. Quatro (23\%) alunos ainda afirmaram terem sido vítimas em jogos online e três não responderam quais foram os meios pelos quais sofreram agressões online.

Sobre a duração das agressões, chama atenção um participante que relatou ser intimidado por mais de três anos e outros três que afirmaram ter sido vítimas por mais de um ano. Nesse sentido, eles atendem ao critério de permanência ao longo do tempo para ser considerado cyberbullying. Além disso, três adolescentes ainda afirmaram terem sido agredidos virtualmente por um curto período de tempo, entre um e três meses. Porém, a maioria, $11(61 \%)$, respondeu ter sido violentada de maneira pontual, por um período menor que um mês. 


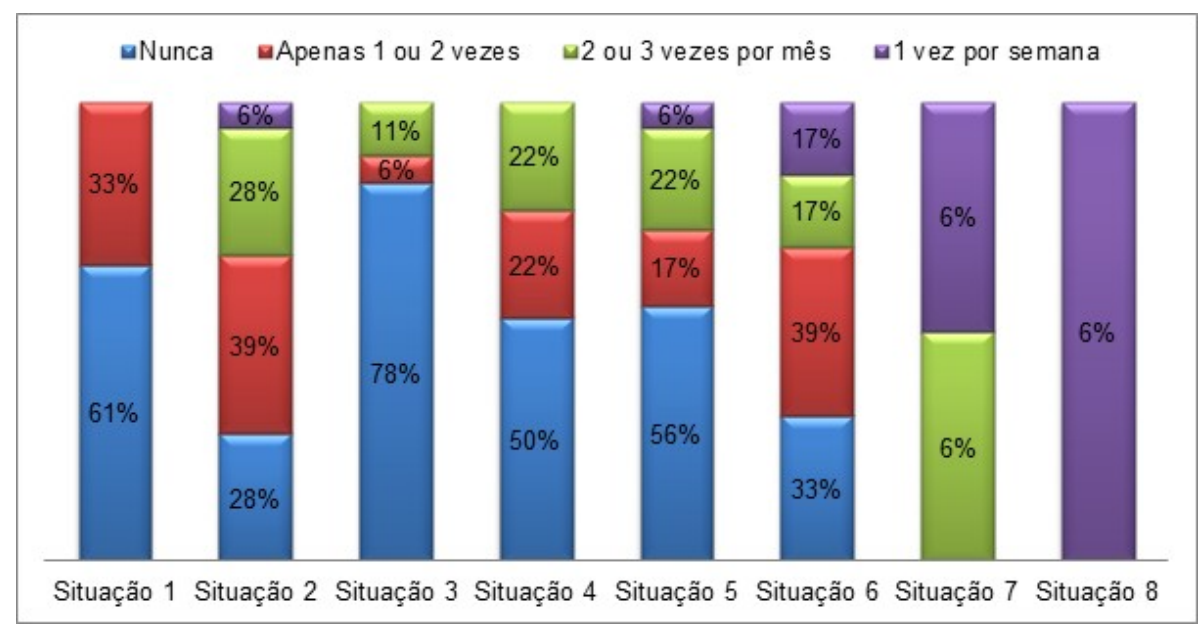

Figura 2. Frequência de vitimização online

Fonte: Dados da pesquisa.

Notas: Situação 1: Entraram no meu e-mail e se passaram por mim; Situação 2: Mensagens hostis por e-mail, redes sociais e/ou aplicativos; Situação 3: Compartilhamento de informações, fotos ou vídeos constrangedores; Situação 4: Exclusão de um jogo ou grupo online; Situação 5: Postagem de mentiras na internet; Situação 6: Falaram mal, ameaçaram ou fizeram piadas na internet; Situação 7: Outra forma como comentar minhas fotos inadequadamente/chacota; Situação 8: Outras formas como através de indiretas.

No que diz respeito às formas de agressões sofridas pelos adolescentes, sete (39\%) afirmaram que receberam mensagens hostis por e-mail, redes sociais ou aplicativos apenas uma ou duas vezes. Porém, cinco $(28 \%)$ relataram que isso ocorria duas ou três vezes por mês e um relatou que isso ocorria pelo menos uma vez por semana. Sete (39\%) alunos também responderam que alguém já falou mal, ameaçou ou fez piadas com eles na internet uma ou duas vezes, outros três afirmaram que isso acontecia duas ou três vezes ao mês. Três pessoas ainda disseram que a frequência era de pelo menos uma vez por semana.

Em relação às postagens de mentiras sobre eles na internet, três alunos responderam que isso ocorreu apenas uma ou duas vezes; quatro, que isso ocorria duas ou três vezes ao mês; e um, que a frequência era pelo menos uma vez por semana. Quatro alunos ainda responderam que foram expulsos de jogos ou grupos online duas ou três vezes por mês e, dois afirmaram que foram compartilhadas informações, fotos ou vídeos constrangedores com a mesma frequência. Tais resultados demonstram intensidade nas agressões sofridas pela maioria dos adolescentes expostos à violência online.

No item referente à identificação do agressor virtual, $11(61 \%)$ colaboradores responderam que sim, identificaram quem foi o agressor online e que eles eram pessoas com quem tinham contato presencial. As principais reações à vitimização online foram: chorar, apontado por sete pessoas (39\%); não reagir, ficar quieto/calado, mencionado por cinco jovens (28\%); quatro (22\%) ainda relatam ter respondido da mesma forma; três $(17 \%)$ 
planejaram vingança; e três (17\%) conversaram com alguém. Apenas um participante respondeu ter reagido realizando uma denúncia e um reagiu pedindo ajuda a outras pessoas. Tais dados demonstram que as estratégias utilizadas por esses jovens são prioritariamente individuais para lidar com o problema. Sete (39\%) pessoas relatam ter reagido de outras formas, entre as quais estão: sentir-se constrangido; manteve a calma e resolveu o problema de forma sensata; ignorou a pessoa; falou com a pessoa, mas ela "não deu a mínima"; e amadureci com a situação.

Quando questionados se a violência virtual teve alguma consequência em suas vidas, $11(61 \%)$ disseram que sim e sete (39\%) disseram que não. Entre os alunos que responderam sim, as principais consequências apontadas foram de ordem psicológica, presentes em 10 dos jovens (91\%), seguidas das sociais em sete (64\%) adolescentes e das físicas, relatadas por cinco $(45 \%)$ deles. Esses dados demonstram as repercussões biopsicossociais da vivência de violência virtual, em que alguns alunos tiveram as três dimensões afetadas em suas experiências. Os estudantes que tiveram mais dimensões afetadas foram justamente os que foram agredidos por maior período e intensidade de tempo.

$\mathrm{Na}$ parte do questionário em que foram apresentados aos alunos cenários hipotéticos de vivências de cyberbullying, houve variação na avaliação da gravidade dos acontecimentos. No Caso 1 - Eduarda, a maioria dos alunos consideraram uma situação Leve, 22 (48\%), enquanto 16 (35\%) consideraram moderado e outros oito (17\%), grave. Já no Caso 2 - João, ninguém considerou a situação como leve, mas seis (13\%) deles consideraram moderado e 40 (87\%), grave. De forma semelhante, nenhuma pessoa avaliou o Caso 3 - Raquel, Leve; 4 (9\%) consideraram moderado e 42 (91\%), grave.

No Caso 4 - Amanda, houve respostas diferentes, pois se sobressaíram avaliações do contexto de violência como moderado, representando 27 (59\%) dos colaboradores e apenas três $(7 \%)$ perceberam a situação como grave. No Caso 5 - Mário, novamente se sobressaem as avaliações da situação como sendo grave, 38 (83\%); seguida da moderada, sete (15\%) e apenas uma avalia a situação como leve. Por fim, no caso 6 Joaquim, $42(91 \%)$ consideram uma situação grave, e quatro (9\%) como moderado, mas nenhuma a considera leve. Observa-se assim que o conteúdo da agressão interfere no senso de gravidade dos jovens, o que pode estar relacionado a aspectos psicossociais de suas experiências.

Ao serem questionados se já realizaram alguma ação semelhante aos dos casos citados, 12 (26\%) afirmaram que sim e 34 (74\%) afirmaram que não. Quanto ao caso que os colaboradores mais se identificam, a maioria, 10 (83\%) relataram identificar-se com o Caso 1 - Eduarda, considerado pela maioria como leve. Enquanto dois (17\%) identificaram-se com o caso de Amanda e Joaquim. Um se interessou pelo caso Raquel e caso Joaquim. Já outro 
aluno se identificou com o caso Raquel e um com o caso Mário. É reconhecido que as respostas dos alunos podem ter sofrido o efeito da desejabilidade social.

\section{DISCUSSÃO}

$\mathrm{Na}$ discussão dos resultados tratamos sobre o panorama da violência virtual e do cyberbullying, comparando os nossos resultados quantitativos com a literatura da área. Discutimos ainda aspectos relacionados as repercussões biopsicossociais das vivências e a eficácia das estratégias utilizadas para lidar com o fenômeno, enfatizando a necessidade de criar modos coletivos e saudáveis enfrentamento. Por fim, apresentamos algumas provocações sobre o papel da escola na prevenção e intervenção diante do cyberbullying para que possamos caminhar no sentido da criação de formas práticas e eficazes de suporte e ajuda.

Um aspecto a ser mencionado em relação ao uso das TICs pelos jovens é a mudança contínua dos aplicativos e sites utilizados, assim como a frequência de uso. Nesta pesquisa, chamou atenção o acesso acima de cinco horas diárias ao WhatApp por $24 \%$ dos participantes; ao aplicativo Instagram e site Youtube (15\%); e a jogos (11\%), além do uso entre três e cinco horas por dia da rede social Facebook (22\%). A pesquisa de Rincón Rueda e Ávila Díaz (2014) demonstra resultados diferentes. Para eles, o Facebook $(58,74 \%)$ apareceu como a rede social mais usada pelos jovens, seguidos do Twitter (18,20\%), que aparece muito pouco em nossa pesquisa, WhatsApp (5,58\%), Instagram (3,64\%) e Youtube $(2,91 \%)$. Sobre o tempo consumido em atividade online, Henriques e Toledo (2014) contribuem ao mostrar aumento de $118 \%$, entre 2012 e 2013 , no uso de redes sociais por crianças e adolescentes, passando de 4,3 milhões para 9,4 milhões e mais de 18 horas mensais conectados. Para eles, a tendência é de que esses números continuem crescendo.

Diante da possibilidade de aumento do tempo despendido online pelos jovens, pode-se pensar em algumas estratégias a serem desenvolvidas na educação para as tecnologias, visando à redução dos riscos na atividade online. Para Guzzi (2014), o crescimento do acesso às redes sociais pelas crianças e adolescentes constitui um indício de maior vulnerabilidade aos riscos das atividades online. Assim, essa autora dá algumas dicas de prevenção de riscos online como a ativação do Safe Search no Google, o acesso a ONG Safer Net, que ministra cursos e campanhas de prevenção de riscos e recebe denúncias de páginas suspeitas de aliciamento ou exposição de crianças e adolescentes.

No que diz respeito às ferramentas de proteção online, apesar da maior parte dos participantes $(80 \%)$ conhecerem bem os mecanismos de proteção, levanta-se o questionamento sobre a efetividade da utilização destes, pois conhecer um processo é diferente de utilizá-lo de forma preventiva e estratégica. Assim, esses adolescentes demonstram utilizar alguns mecanismos de proteção, como não abrir links ou anexos de 
pessoas desconhecidas e não partilhar informações pessoais com elas (63\%), mas não outros, como contatar o servidor quando é perseguido online (2\%). Uma pesquisa de Campos (2009) verificou que os agressores eram os que mais conheciam as estratégias de proteção online e as utilizavam para garantir o anonimato dos atos. Em nossa pesquisa não foi possível identificar essa diferenciação, tendo em vista que a maior parte dos jovens estavam envolvidos ao mesmo tempo como vítimas (39\%) e agressores (26\%) nas manifestações de cyberbullying.

A incidência de agressões online encontrada nesta pesquisa foi maior do que o relatado na literatura, o que nos leva a pensar que existem aspectos na dinâmica das relações interpessoais dos jovens na escola estudada os quais podem favorecer a ocorrência de cyberbullying. Outras pesquisas, como a de Rincón Rueda e Ávila Díaz (2014), mostraram que $11,83 \%$ dos participantes sofreram assédios, ameaças ou continuação de agressões presenciais. Dados semelhantes são vistos em Varela, Pérez, Schwaderer, Astudillo e Lecannelier (2014), em que 11,4\% relataram ser vítimas no ciberespaço. Números maiores foram encontrados por Prieto, Carrillo e Lucio (2015), para os quais entre $20 \%$ e $40 \%$ foram vítimas de violência habitual e, por Navarro e Yubero (2012), que identificaram 27,95\% de vítimas de cyberbullying.

Considera-se que outros aspectos, além da lógica e racionalidade, interferem na forma como os jovens se relacionam online. Mesmo conhecendo a importância da proteção, se certos mecanismos forem vistos pelo grupo como desnecessários, o jovem pode negligenciar alguns cuidados, ou se expor na internet de modo inseguro, seja por incentivo dos pares ou busca de visibilidade e reconhecimento social. Como afirma Bauman (2004), a maioria das inovações tecnológicas encurtam distâncias entre impulso e satisfação, porém, ao mesmo tempo, tornam as relações mais superficiais. Assim, em um movimento de transformações rápidas e contínuas, os jovens pouco orientados podem se envolver em diferentes situações de exposição pela necessidade de satisfação imediata e construção de vínculos.

Nesta pesquisa, as ferramentas mais relatadas pelos jovens para intimidações online foram o Facebook (61\%) e o WhatsApp (33\%), o que parece estar de acordo com a literatura, tendo em vista serem dois meios de comunicação online bastante utilizados no Brasil. A pesquisa de Souza (2016), por exemplo, encontrou resultados semelhantes ao comparar a incidência de cyberbullying no Brasil e em Portugal, pois 65,9\% dos casos de cyberbullying ocorriam pelo Facebook, seguidos de 24,8\% pelo WhatsApp. Menay-López e Fuente-Mella (2014) também apontam nesta direção ao evidenciarem como plataforma de comunicação mais utilizada para o cyberbullying o Facebook, com a diferença de que alunos de nível socioeconômico médio utilizam como ferramenta de acesso telefones celulares e 
computadores, enquanto alunos de nível socioeconômico alto fazem isso por meio de notebooks, iPads e smartphones.

Nesta pesquisa, um número considerável de adolescentes identificou seus agressores, o que pode estar relacionado ao cyberbullying como continuidade de agressões presenciais ocorridas na escola, como demonstra a literatura. Santander (2013) e Amemiya et al (2013), por exemplo, demonstram que a maioria dos ataques online ocorrem entre os mesmos alunos, pois mesmo havendo anonimato dos agressores na internet, geralmente os atores envolvidos se conhecem, de modo que o cyberbullying ocorre principalmente entre amigos, antigos amigos ou colegas, mas é incomum entre estranhos. Por isso, segundo Prieto, Carrillo e Lucio (2015), o cyberbullying pode ser até mais grave do que o bullying tradicional.

Em relação às estratégias das vítimas para lidar com as agressões online, Castillo (2010) descreve estratégias de enfrentamento como manejo de esforços para lidar com demandas específicas, em aspectos cognitivos ou comportamentais. Nesse sentido, elas atuam sobre as situações e os significados percebidos pelos sujeitos da experiência. Exemplos de estratégias de enfrentamento interessantes para lidar com o cyberbullying são: pedir ajuda a outras pessoas, denunciar o agressor, se posicionar assertivamente frente as agressões, conversar com alguém sobre o problema, entre outras. Porém, esta pesquisa demonstrou, prioritariamente, o uso de estratégias de evitamento as intimidações, como chorar (39\%) e não reagir (28\%), seguido de estratégia de confronto como realizar $(22 \%)$ e planejar (17\%) vingança. Observa-se que essas formas de lidar com o cyberbullying são individuais, sendo feitas de maneira isolada pelo sujeito da experiência que parece encontrar dificuldade em solicitar e conseguir apoio em seu meio social. Essas estratégias individuais podem ser insuficientes para cessar com as agressões de maneira imediata. Desse modo, considera-se a relevância de desenvolver nos jovens habilidades sociais e estratégias coletivas mais eficazes para enfrentar as agressões online (Navarro \& Yubero, 2012). Estas devem ser pensadas tanto no sentido da prevenção como em intervenções resolutivas diante de intimidações já em andamento.

Souza, Veiga Simão e Caetano (2014) demonstram que estratégias como fazer frente ao fato, contatar as autoridades policiais, procurar ajuda de alguém de confiança e pedir ajuda aos amigos, funcionam como importantes mecanismos e devem ser usadas pelas vítimas no contexto off-line. Esses autores chamam atenção ainda para a necessidade de utilização dos mecanismos de proteção online como excluir os agressores das redes sociais e contatar os gestores do site ou rede social. Nesse sentido, considera-se a necessidade de criação de estratégias coletivas, envolvendo múltiplos atores como escola, família, saúde, segurança e sociedade em geral, como caminho diante da complexidade da nossa cibercultura. 
No que diz respeito às repercussões das vivências de cyberbullying, os resultados identificaram, principalmente, aspectos psicológicos (91\%) e sociais (64\%). Confrontando com a literatura, observa-se que esses fatores são também observados por autores como Prieto et al, (2015), os quais mostraram que, além do medo, existe desconfiança e paranoia, pelo menos na população estudada, enquanto García-Maldonado et al (2012) encontraram 13\% das vítimas apresentando medo dos agressores. Rincón Rueda e Ávila Díaz (2014) também abordaram o temor dos jovens em expressar qualquer evidência de ataque. Além disso, Azevedo, Miranda e Souza (2012) indicaram que as vítimas, expostas a situações de humilhações e agressões psíquicas ou físicas, podem adquirir vários transtornos, entre eles: baixa autoestima, depressão, ideações/comportamentos suicidas, entre outros, além de poderem manifestar violência ao agressor ou a outras pessoas do meio social. Esses e outros aspectos serão discutidos a seguir considerando uma compreensão fenomenológica da experiência dos adolescentes com o cyberbullying.

O cyberbullying encontra relação com o ambiente escolar, pois o contexto das relações estabelecidas entre os jovens é perpassado por aquilo que faz parte de suas realidades, sendo o ambiente escolar o espaço físico privilegiado de interações entre os adolescentes, que se aprofundam e têm continuidade no ambiente virtual. Nesse sentido, a comunidade escolar tem um papel importante na prevenção e intervenção diante do cyberbullying.

Assim, no âmbito da equipe escolar, considera-se a necessidade de formação e treinamento de seus atores sobre este fenômeno para que possam sentir-se preparados para adotar uma postura ativa na identificação e resolução dos conflitos, orientação e fortalecimento dos educandos no enfrentamento ao problema. Um ambiente educativo acolhedor e colaborativo pode auxiliar os alunos a explorar o tema sem medo de serem banalizados ou desacreditados.

Sobre essa questão, Perfeito, Silveira, Lima e Barros (2015) discutem sobre as falhas no sistema de ensino brasileiro no estímulo reflexivo entre professores, alunos e funcionários quando o assunto é a prevenção e intervenção em casos de violência e preconceito, nos quais pode-se incluir também o bullying e o cyberbullying. Esses autores demonstram que ações pontuais e simplistas não são efetivas para solucionar o problema.

Entendemos que este é um grande desafio. Como iniciativas nesse sentido, é interessante considerar experiências exitosas de outros países que podem ser usadas como inspiração para pensar em ações brasileiras. Como no caso do programa de intervenção realizado por Pérez, Astudillo, Varela e Lecannelier (2013) para lidar com o bullying e o cyberbullying nas escolas chilenas, cuja avaliação dos resultados demonstrou redução significativa na percepção dos participantes de ser vítima de intimidação presencial e online. 
O impacto desse programa ainda é reduzido, mas alerta para o desafio de alcançar intervenções mais profundas e eficientes.

Em nosso estudo, as ações consideradas pelos adolescentes que poderiam ajudar a lidar com os agressores envolveram palestras e campanhas de conscientização, o desenvolvimento da empatia, observação e controle por parte dos educadores e gestão escolar e a tomada de providências junto à família. É preciso compreender que para que essas e outras ações possam galgar resultados significativos, elas precisam ser tomadas não apenas como ações pontuais e simplistas, mas como parte da política da escola, de modo a fazer parte do cotidiano escolar em ações continuadas como planejamento, execução, avaliação, ajustes e implementação, para que, aos poucos, possam se tornar parte da cultura escolar.

\section{CONCLUSÕES}

Ao pesquisar sobre as vivências de adolescentes com o cyberbullying na cidade de Juazeiro-BA, compreendemos aspectos significativos sobre esse fenômeno complexo e suas repercussões na vida destes jovens. Em nosso contexto de estudo, identificamos uma incidência considerável de estudantes do ensino médio que passaram por episódios de agressões no ambiente virtual, seja na posição de vítima, de agressor ou ambas. Entre estes jovens, chamaram a atenção aqueles cujas agressões se caracterizaram como o que a literatura vem denominando de cyberbullying.

Neste estudo foi possível compreender que as estratégias mobilizadas pelos participantes na tentativa de lidar com o fenômeno prioritariamente de evitamento e fuga do problema, como chorar (39\%) e não reagir (28\%), assim como estratégia de confronto como realizar $(22 \%)$ e planejar (17\%) vingança, de modo que as estratégias de enfrentamento, como pedir ajuda, conversar sobre o problema e denunciar as agressões, foram pouco utilizadas. Tais estratégias foram prioritariamente individuais, o que demonstrou dificuldade nos jovens em recorrer à ajuda de outras pessoas no ambiente social. As experiências com o cyberbullying foram perpassadas prioritariamente por repercussões psicológicas, o que está de acordo com a literatura da área.

Como limitações deste estudo, consideramos a restrição ao contexto específico de uma escola particular e a inclusão de adolescentes apenas do ensino médio. Pois, sabemos que o cyberbullying pode ocorrer com jovens dos mais variados níveis escolares e que o campo estudado não representa a totalidade de experiências na cidade de JuazeiroBA. Nesse sentido, sugerimos como pesquisas futuras, estudar o cyberbullying entre estudantes do ensino fundamental I e II, compreender as experiências de jovens também de escolas públicas, assim como abranger o campo de estudo para outras cidades além de 
Juazeiro-BA, que também façam parte da região do Vale do São Francisco, a fim de verificar especificidades locais e aspectos culturais do fenômeno.

Este estudo visou contribuir com o debate científico sobre o cyberbullying e pretendeu enriquecer o aporte teórico em estudos brasileiros na interface saúde, educação e novas tecnologias. Como possível desdobramento prático, consideramos a possibilidade de colaborar com a construção de atitudes preventivas, estratégias de cuidado à saúde e medidas educacionais e de enfrentamento efetivas para lidar com o problema, diante dos riscos físicos, psicológicos e sociais que o fenômeno pode causar para a geração de nativos digitais.

É difícil nos dias atuais fugir ou viver alheio às inovações tecnológicas e às características da sociedade que nos é apresentada. O desafio é desenvolver um olhar para a coletividade, para o suporte mútuo, sensível ao outro e ao mundo, assim como o uso consciente das tecnologias e de todos os potenciais que elas dispõem, pois podem fazer toda a diferença no caminho para o enfrentamento do cyberbullying.

\section{REFERÊNCIAS}

Amemiya, I., Oliveros, M., Condorimay, Y., Oliveros, R., Barrientos, A., \& Rivas, B.E. (2013). Ciberbullying en colegios privados y estatales de primaria en dos distritos de Lima Metropolitana. Anales de la Facultad de Medicina. 74(2), pp. 91-6. Recuperado de: http://revistasinvestigacion.unmsm.edu.pe/index.php/anales/article/view/2379/2078

Almeida, M. R. (2009). O tempo como moeda de valor na cultura digital.Contemporânea, 7(1). Recuperado de:

http://www.contemporanea.uerj.br/pdf/ed_12/contemporanea_n12_05_melissa.pdf

Andrade, L. C. F. (2012). Bullying e Cyberbullying: Um estudo num contexto escolar particular cooperativo.(Dissertação de mestrado, Universidade da Madeira). Recuperado de: http://hdl.handle.net/10400.13/422

Azevedo, J.C., Miranda, F.A., \& Souza, C.H.M. (2012). Reflexões a cerca das estruturas psíquicas e a prática do Ciberbullying no contexto da escola. Revista Brasileira de Ciências da Comunicação. 35(2), pp. 247-265. Recuperado de: http://www.scielo.br/pdf/interc/v35n2/13.pdf

Barbosa, A.F. (Eds.) (2014). TIC Kids Online Brasil 2013: pesquisa sobre o uso da Internet por crianças e adolescentes no Brasil. Brasil: Comitê Gestor da Internet no Brasil CGI.br. (1), 05-323. Recuperado de: http://cetic.br/media/docs/publicacoes/2/tic-kidsonline-2013.pdf

Barbosa, D.R., \& Souza, M.P.R. (2012). Psicologia Educacional ou Escolar? Eis a questão. Psicol. Esc. Educ., Maringá. 16 (1), pp. 163-173. Recuperado de: http://www.scielo.br/scielo.php?script=sci_arttext\&pid=S1413$85572012000100018 \&$ lng $=e n \& n r m=i s o$

Bauman, Z. (2004). Amor líquido: sobre a fragilidade dos laços humanos. Rio de Janeiro: Jorge Zahar Ed., p. 22. 
Brown, K., Jackson, M., \& Cassidy, W. (2006). Cyber-bullying: developing policy to direct responses that are equitable and effective in addressing this special form of bullying. Canadian Journal of Educational Administration and Policy, 57(1), 1-35. Recuperado de: https://umanitoba.ca/publications/cjeap/articles/brown_jackson_cassidy.html

Calvete, E., Orue, I., Estévez, A., Villardón, L., \& Padilla, P. (2010). Cyberbullying in adolescents: Modalities and aggressors' profile. Computers in Human Behavior, 26, 1128-1135. Recuperado de: http://www.sciencedirect.com/science/article/pii/S0747563210000579

Campos, M. (2009). O Cyberbullying. Natureza e Ocorrência em Contexto Português. (Dissertação de mestrado, Instituto Universitário de Lisboa). Recuperado de: https://repositorio.iscteiul.pt/bitstream/10071/1884/1/O\%20Cyberbullying \%20em $\% 20$ Contexto $\% 20$ Portugu $\%$ C3 \%AAs\%20-\%20Mariana\%20Campos.pdf

Casttels, M. (1999). A sociedade em rede: a era da informação: economia, sociedade e cultura. (8). São Paulo: Paz e Terra.

Castillo, A. E. (2010). Estudio descriptivo de las estratégias de afrontamiento del bullying, en professorado mexicano. Electronic Journal of Research in Educational Phychology, 8(1), 353-372. Recuperado de: http://www.investigacionpsicopedagogica.org/revista/new/ContadorArticulo.php?426

Cruz, T. (2000). Sistemas de informações gerenciais - tecnologia da informação e a empresa do século XXI. São Paulo: Atlas. (2).

Cozby, P.C. Métodos de Pesquisa em Ciências do Comportamento. São Paulo: Atlas.

Dal Cin, I.C.T.P. (2013). Dependência de Internet: Um Estudo com Profissionais e Estudantes da área de TI em Belo Horizonte. (Dissertação de Mestrado, Faculdade Novos Horizontes). Recuperado de: http://unihorizontes.br/novosite/banco_dissertacoes/190820131715368063.pdf

Fonseca, J. J. S. (2002). Metodologia da pesquisa científica. Fortaleza: UEC.

García-Maldonado, G., Martínez-Salazar, G.J., Saldívar-González, A.H., Sánchez-Nuncio, R., Martínez-Perales, G.M., \& Barrientos-Gómez, M.C. (2012). Factores de riesgo y consecuencias del cyberbullying en un grupo de adolescentes. Asociaciónconbullying tradicional. Boletín médico del Hospital Infantil de México. 69(6), pp. 463-474.

Recuperado de: http://www.scielo.org.mx/pdf/bmim/v69n6/v69n6a7.pdf

Guzzi, D. (2014). Diálogo, Configurações de Privacidade e Compartilhamento: aja, não seja só um espectador. _In. Barbosa, A.F. (Eds.), TIC Kids Online Brasil 2013: pesquisa sobre o uso da Internet por crianças e adolescentes no Brasil. Brasil: Comitê Gestor da Internet no Brasil - CGI.br. (1), 05-323. Recuperado de:

http://cetic.br/media/docs/publicacoes/2/tic-kids-online-2013.pdf

Henriques, I., \& Toledo, R.G. (2014). A Complementaridade entre os Canais Infantis, seus Sitese e Perfis em Redes Sociais: uma nova estratégia de comunicação mercadológica voltada às crianças. _.In. Barbosa, A.F. (Eds.), TIC Kids Online Brasil 2013: pesquisa sobre o uso da Internet por crianças e adolescentes no Brasil. Brasil: Comitê Gestor da Internet no Brasil - CGI.br. (1), 05-323. Recuperado de:

http://cetic.br/media/docs/publicacoes/2/tic-kids-online-2013.pdf 
Lévy, P. (1999). Cibercultura. São Paulo: Ed. 34, 08-264.

Menay-López, L., \& Fuente-Mella, H. (2014). Plataformas comunicacionales del ciberbullying. Una aplicación empírica en dos colegios de la quinta región, Chile. Estudios Pedagógicos XL. (2), pp. 117-133. https://scielo.conicyt.cl/pdf/estped/v40n2/art07.pdf

Navarro, R., \& Yubero, S. (2012). Impacto de la ansiedad social, las habilidades sociales y la cibervictimización en la comunicación online. Escr Psicol. 5(3), pp. 4-15. Recuperado de: https://ruidera.uclm.es/xmlui/bitstream/handle/10578/2939/fi_1357635991vol5num32.pdf? sequence $=1 \&$ isAllowed $=y$

Oliveira, K. M. R. (2012). Experiências de Adolescentes com Bullying Escolar e Análise Fenomenológica de suas Vivências. (Dissertação de Mestrado, Universidade Estadual Paulista - Faculdade de Ciências). Recuperado de: http://200.145.6.238/bitstream/handle/11449/97466/oliveira_kmr_me_bauru.pdf?sequen $\mathrm{ce}=1$ \&isAllowed $=\mathrm{y}$

Olweus, D. (1997). Bully/victim problems in school: Facts and intervention. European Journal of Psychology of Education.1991.XII, (4), 495-510.Recuperado de: http://www.episcenter.psu.edu/sites/default/files/news/Olweus\%20(1997)\%20Bullyvictim $\% 20$ problems $\% 20$ in $\% 20$ school.pdf

Patchin, J. W., \& Hinduja, S. (2010). Cyberbullying and Self-Esteem.Journal of School Health, 80(12),614-621.http://dx.doi.org/10.1111/j.1746-1561.2010.00548.

Perfeito, R.S., Silveira, D.S., Lima, M.F.C., \& Barros, C.F. (2015). Caso Amanda Todd: uma oportunidade de refletir o cyberbullying na escola. Educação Física em Revista - EFR. 9(1), p. 33-53. https://portalrevistas.ucb.br/index.php/efr/article/view/5436/4549

Pérez, J.C., Astudillo, J., Varela, J. T., \& Lecannelier, F.A. (2013). Evaluación de la efectividad del Programa Vínculos para la prevención e intervención del Bullying en Santiago de Chile. Revista Semestral da Associação Brasileira de Psicologia Escolar e Educacional, SP.17(1), pp. 163-172. Recuperado de: http://www.scielo.br/pdf/pee/v17n1/a17v17n1.pdf

Prieto, M.T., Carrillo, J.C., \& Lucio, L.A. (2015). Violencia virtual y acoso escolar entre estudiantes universitarios: el lado oscuro de las redes sociales. Innovación. Educativa. 15(68). Recuperado de: http://www.scielo.org.mx/pdf/ie/v15n68/v15n68a4.pdf

Rincón Rueda, A. I. \& Ávila Díaz, W. D. (2014). Simbiosis vital para describir el ciberbullying en Colombia. Revista Científica General José María Córdova. 12(14), pp. 149-164. Recuperado de: http://www.redalyc.org/articulo.oa?id=476247222009

Rondina, J.M., Moura, J.L., \& Carvalho, M.D. (2016). Cyberbullying: o complexo bullying da era digital. Re. Saúd. Digi. Tec. Edu. Fortaleza, CE. 1(1), 20-41. Recuperado de: http://periodicos.ufc.br/resdite/article/view/4682/3485

Santander, A.S. (2013). Formar para laciberconvivencia Internet y prevencióndel cyberbullying. Integra Educativa.6 (2). Recuperado de: http://www.scielo.org.bo/pdf/rieiii/v6n2/v6n2a04.pdf

Soares, A. K. S. (2013). Valores humanos e bullying: Um estudo pautado na congruência entre pais e filhos. (Dissertação de Mestrado, Universidade Federal da Paraíba). Recuperado de: 
https://docs.google.com/viewerng/viewer?url=http://tede.biblioteca.ufpb.br:8080/bitstrea $\mathrm{m} /$ tede/6927/1/arquivototal.pdf

Souza, S. B., Veiga Simão, A. M. \& Caetano, A. P. (2014). Cyberbullying: Percepções acerca do Fenômeno e das Estratégias de Enfrentamento. Psicologia: Reflexão e Crítica, 27(3), pp. 582-590. http://dx.doi.org/10.1590/1678-7153.201427320

Souza, A.V., \& Lima, A.M. (2016). Cyberbullying: violência na rede uma abordagem no ensino municipal de Ministro Andreazza. Revista Científica da UNESC. 14(1), pp. 11-21. Recuperado de: http://revista.unescnet.br/index.php/revista/article/view/369/267

Varela, J.T., Pérez, J.C., Schwaderer, H.Z., Astudillo, J., \& Lecannelier, F.A. (2014). Caracterización de cyberbullying en el gran Santiago de Chile, en el año 2010. Revista Quadrimestral da Associação Brasileira de Psicologia Escolar e Educacional, SP. 18(2), pp. 347-354. http://dx.doi.org/10.1590/ 2175-3539/2014/0182794

Wendt, G. W., \& Lisboa, C. S. M. (2013). Agressão entre pares no espaço virtual: definições, impactos e desafios do cyberbullying. Psicologia Clínica, Rio de Janeiro, 25(1), 73-87. http://dx.doi.org/10.1590/S0103-56652013000100005.

\section{NOTA SOBRE OS(AS) AUTORES(AS):}

Liberalina Santos de Souza Gondim - Psicóloga, Mestra em Psicologia. Universidade Federal do Vale do São Francisco (UNIVASF). E-mail: Ii-gondim@hotmail.com

Marcelo Silva de Souza Ribeiro - Psicólogo, Mestre em Educação em Pesquisa, Doutor em Ciências da Educação. Universidade Federal do Vale do São Francisco (UNIVASF). E-mail: mribeiro27@gmail.com

Recebido em: 27/01/2018. Aprovado em: 07/04/2019. 